Military Technical College Kobry El-Kobbah, Cairo, Egypt

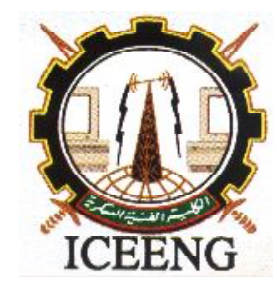

$9^{\text {th }}$ International Conference on Electrical Engineering ICEENG 2014

\title{
Stability Analysis of Synchronous Generator among Four Intelligent Fuzzy Logic Based Excitation Controllers
}

\author{
By \\ W. Sabry*
}

\section{$\underline{\text { Abstract: }}$}

Electrical power systems are widely distributed systems, consisting of a large number of interconnected synchronous generators through transmission lines, mounting real and reactive power. Moreover, with deregulation and growth of the power industry, power systems elements are forced to operate very near to their maximum capacity and hence, the system becomes vulnerable. Therefore, controlled operation of power systems is very critical and of utmost importance in order to achieve stable power system. Naturally, this paves ways for implementing fast, efficient and reliable control algorithms. Robustness and efficiency of power system controllers can be improved by using complimentary models of intelligent systems. Difficulties encountered in designing controls for nonlinear, dynamic and uncertain systems can be easily tackled by using intrinsic observability property of various intelligent systems. Intelligent controllers have been successfully applied to enhance operation and control of power system. This paper presents an implementation of four different Fuzzy Logic based intelligent controllers through the excitation system of the synchronous generator: Conventional Fuzzy Logic Controller (CFLC), Adaptive Fuzzy Logic Controller (AFLC), Adaptive Neuro-Fuzzy Logic Controller (ANFLC) and Takagi-Sugeno Fuzzy Logic Controller (TSFLC). A comparison between the four proposed intelligent controllers are presented.

Keywords:

Conventional Fuzzy Logic Controller (CFLC), Adaptive Fuzzy Logic Controller (AFLC), Adaptive Neuro-Fuzzy Logic Controller (ANFLC), Takagi-Sugeno Fuzzy Logic Controller (TSFLC)

* Egyptian Armed Forces 


\section{Introduction:}

Understudy systems are continuously increasing in size in national and international levels. Inter-connected unified networks installed in nearly all countries and continent. Consumers demand of electricity increases day after day allover the world. Stable operation of such large under study system is a necessity for all people. According to these interconnections, the systems orders become relatively high and the complexity is increased. Therefore, the analysis of dynamic stability and controller's design of these large interconnected under study systems becomes difficult [1-2].

In the past fixed gain controllers were effectively used for damping out the low frequency oscillations. These stabilizers are designed based on linearized model of power systems for a particular operating and system condition. They are unable to maintain their performance in constantly changing operating conditions of highly nonlinear, interconnected power systems of today. They are also not very effective in damping out the characteristic multimodal oscillations of interconnected system [3].

Adaptive stabilizers. which could track the changes in system dynamics in real time should be in principle able to perform well for all network and operating conditions. Stabilizer design based on adaptive control techniques, such as model reference adaptive control, self tuning control and gain scheduling have been extensively reported in literature, which appear to have better performances than the conventional stabilizer. Use of adaptive stabilizers has however not become popular in actual power plants due to various constraints such as complexity of design, extensive real-time computational requirements, and possible non-convergence and numerical instability of the control algorithms [4].

With recent advancement in Robust control technology, there has been a sustained effort to design robust power system stabilizer which could maintain its performance in spite of changes in system dynamics due to changes in network and operating conditions. It is however often not possible to achieve the desired performance with the degree of robustness required over the entire range of operating condition [5].

In recent years fuzzy logic based controllers have been suggested for PSS design. These are model-free controllers, i.e. the exact mathematical model of the controlled system is not required. The control strategy depends upon a set of rules which describes the behavior of the controller. The ability to handle changes in plant parameters due to changes in operating and system conditions and the ability of self tuning of parameters to a certain extent are in-built in such design process [6]. 
Moreover, different Fuzzy Logic based intelligent controllers appeared in the past few years. In this paper, three of those controllers namely: Adaptive Fuzzy Logic Controller (AFLC), Adaptive Neuro-Fuzzy Logic Controller (ANFLC) and Takagi-Sugeno Fuzzy Logic Controller (TSFLC); are compared to the Conventional Fuzzy Logic Controller (CFLC), when used as excitation system control of the synchronous generator.

\section{Synchronous Machine Connected to Infinite Bus:}

The synchronous machine under study is connected to an infinite bus through a transmission line as shown in Figure (1), is modeled by a $13^{\text {th }}$ order model. This model contains $5^{\text {th }}$ order model for winding representation of synchronous machine, $4^{\text {th }}$ order model for automatic voltage regulator (AVR) and exciter and $4^{\text {th }}$ order model for turbine and speed governor [7].
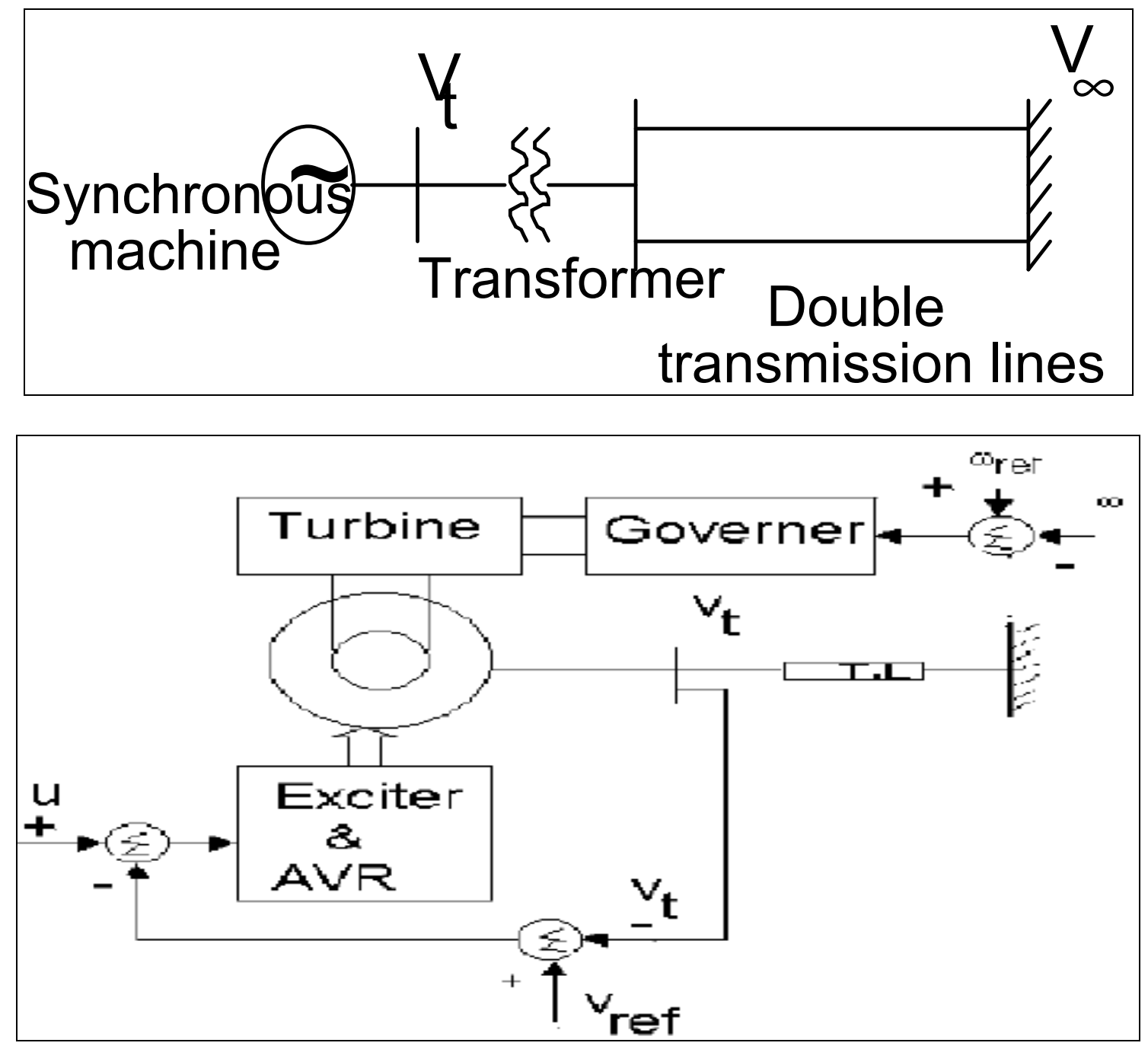

Figure (1): Schematic diagram of synchronous machine connected to an infinite bus 
The matrix form for the synchronous machine connected to an infinite bus model is:

$$
\begin{aligned}
& x=A x+B u \\
& A_{1} x+\frac{1}{\omega_{b}} A_{2} x=B u
\end{aligned}
$$

From the above equations, the A matrix can be written as:

$$
A=-\omega_{b} A_{2}^{-1} A_{1}
$$

Elements of A-matrix are defined in appendix [A], where:

$$
\begin{aligned}
& x=\left[\begin{array}{lllllllllllll}
\Delta i_{q} & \Delta i_{d} & \Delta i_{k q} & \Delta i_{k d} & \Delta i_{f} & \Delta \delta & \Delta \omega & \Delta E_{f d} & \Delta V_{a} & \Delta V_{r} & \Delta V_{s} & \Delta P_{m} & \Delta P_{g}
\end{array}\right]^{T} \\
& u=\left[\begin{array}{llll}
\Delta P_{L} & \Delta V_{c} & \Delta P_{c}
\end{array}\right]
\end{aligned}
$$

$A_{1}=\left[\begin{array}{ccccccccccccc}-\left(r_{a}+r_{l}\right) & -\left(x_{d}+x_{l}\right) & 0 & x_{m d} & x_{m d} & v_{b} \sin \delta_{0} & \frac{\psi_{d} 0}{\omega_{b}} & 0 & 0 & 0 & 0 & 0 & 0 \\ -\left(x_{q}+x_{l}\right) & -\left(r_{a}+r_{l}\right) & x_{m q} & 0 & 0 & -v_{b} \cos \delta_{0} & \frac{\psi_{q 0}}{\omega_{b}} & 0 & 0 & 0 & 0 & 0 & 0 \\ 0 & 0 & x_{k q} & 0 & 0 & 0 & 0 & 0 & 0 & 0 & 0 & 0 & 0 \\ 0 & 0 & 0 & r_{k d} & 0 & 0 & 0 & 0 & 0 & 0 & 0 & 0 & 0 \\ 0 & 0 & 0 & 0 & x_{m d} & 0 & 0 & 0 & 0 & -1 & 0 & 0 & 0 \\ 0 & 0 & 0 & 0 & 0 & 0 & 1 & 0 & 0 & 0 & 0 & 0 & 0 \\ \frac{E 1}{M} & \frac{E 2}{M} & \frac{E 3}{M} & \frac{E 4}{M} & \frac{E 5}{M} & 0 & \frac{-D}{M} & 0 & 0 & 0 & 0 & 0 & 0 \\ 0 & 0 & 0 & 0 & 0 & 0 & 0 & \frac{-1}{T_{e}} & \frac{K_{e}}{T_{e}} & 0 & 0 & 0 & 0 \\ 0 & 0 & 0 & 0 & 0 & 0 & 0 & 0 & \frac{-1}{T_{a}} & \frac{-K_{a}}{T_{a}} & \frac{-K}{T_{a}} & 0 & 0 \\ M 10,1 & M 10,2 & 0 & 0 & 0 & M 10,6 & M 10,7 & 0 & 0 & \frac{-1}{T_{r}} & 0 & 0 & 0 \\ 0 & 0 & 0 & 0 & 0 & 0 & 0 & 0 & \frac{-K K_{s}}{T_{s} T_{e}} & \frac{K_{e} K_{s}}{T_{s} T_{e}} & \frac{-1}{T_{s}} & 0 & 0 \\ 0 & 0 & 0 & 0 & 0 & 0 & 0 & 0 & 0 & 0 & 0 & \frac{-1}{T_{t}} & \frac{-1}{T_{s}} \\ 0 & 0 & 0 & 0 & 0 & \frac{1}{T_{g} R_{g}} & 0 & 0 & 0 & 0 & 0 & 0 & \frac{-1}{T_{g}}\end{array}\right]$ 


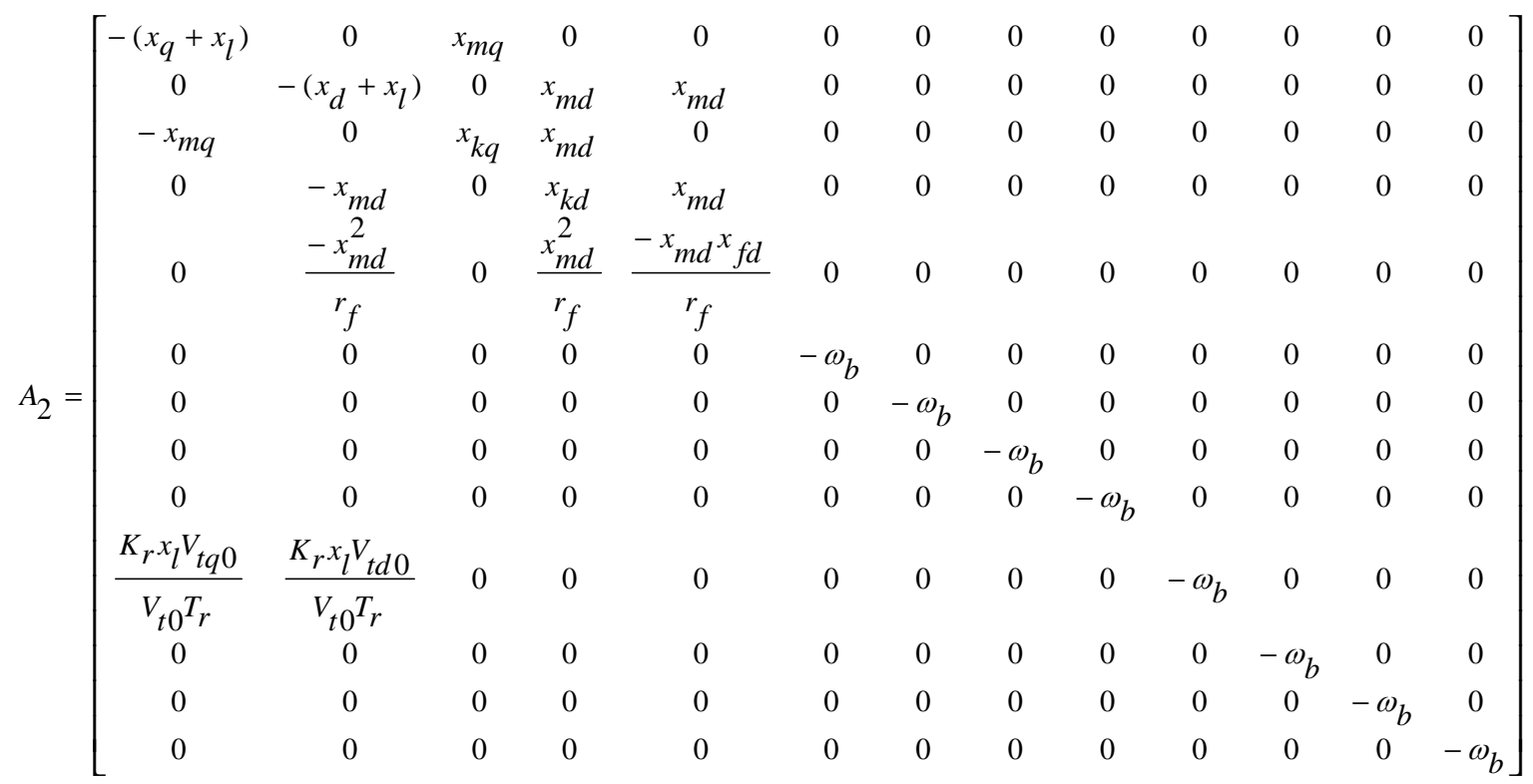

$B=\left[\begin{array}{ccccccccccccc}0 & 0 & 0 & 0 & 0 & 0 & \frac{1}{M} & 0 & 0 & 0 & 0 & 0 & 0 \\ 0 & 0 & 0 & 0 & 0 & 0 & 0 & 0 & \frac{K a}{T a} & 0 & 0 & 0 & 0 \\ 0 & 0 & 0 & 0 & 0 & 0 & 0 & 0 & 0 & 0 & 0 & 0 & \frac{1}{T g}\end{array}\right]^{t}$

\section{CFLC:}

The first step in designing the FLC is the determination of the state variables which are used for evaluation of the performance of the system. The input signals to the FLC are to be chosen from these variables. Since the main objective of the controller is to limit the variations in the power angle, deviation of power angle derivative $(\omega)$ and deviation of speed derivative ( $\dot{\omega}$ ) are chosen to be the input to FLC. Each control rule consists of an "IF situation THEN action" pair. The "IF" portion of the rule is called the premise or antecedent, while the "THEN" part is the consequent. The premise defines a region of the input space wherein the rule is valid. This region is characterized by a fuzzy set on the discourse of the input variable. The consequent defines the desired control action to be taken for the input space delimited by the premise. The following fuzzy sets for input signals $\omega$ and $\dot{\omega}$ are defined as:

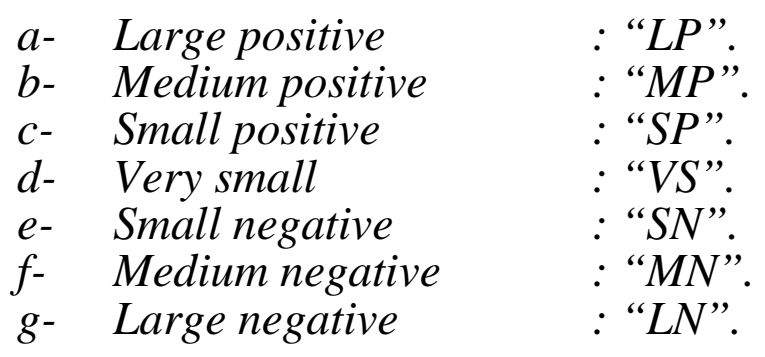


According to the control principle of the PSS, the control rules can be constructed based on the values of $\omega$ and $\dot{\omega}$. For example : IF $\Delta \omega$ value is LP and $\dot{\omega}$ value is LN, THEN the control action (u) should be VS . The above IF-THEN rule is a fuzzy description of the control logic representing the human expert's value, a set of fuzzy control rules similar to the above can be obtained. An example set of rules is shown in Table (1).

Table (1): Example of fuzzy logic control rules

\begin{tabular}{||c||c|c|c|c|c|c|c||}
\hline \hline$\omega / \dot{\omega}$ & LN & MN & SN & VS & SP & MP & LP \\
\hline \hline LN & LN & LN & LN & LN & MN & SN & VS \\
\hline MN & LN & LN & MN & MN & SN & VS & SP \\
\hline SN & LN & MN & SN & SN & VS & SP & MP \\
\hline VS & MN & SN & VS & SP & SP & MP & LP \\
\hline SP & MN & SN & VS & SP & SP & MP & LP \\
\hline MP & SN & VS & SP & MP & MP & LP & LP \\
\hline LP & VS & SP & MP & LP & LP & LP & LP \\
\hline
\end{tabular}

In order to properly describe the input signals, it is necessary to specify certain thresholds for $\omega$ and $\dot{\omega}$ according to the expert's knowledge and to define their membership values as shown in Table (2). According to Table (1), the fuzzy relation matrix can be constructed. However, since the fuzzy relation matrix usually has very high dimension (49 for the last example), it is inconvenient and unnecessary to store the relation matrix directly.

Table (2): Membership values of $\omega$ and $\dot{\omega}$

\begin{tabular}{||c||c|c|c|c|c|c|c||}
\hline$\omega / \dot{\omega}$ & LN & MN & SN & VS & SP & MP & LP \\
\hline \hline-1.0 & 1.0 & 0.5 & 0.0 & 0.0 & 0.0 & 0.0 & 0.0 \\
\hline-0.2 & 0.0 & 1.0 & 0.5 & 0.0 & 0.0 & 0.0 & 0.0 \\
\hline-0.1 & 0.0 & 0.5 & 1.0 & 0.5 & 0.0 & 0.0 & 0.0 \\
\hline-0.05 & 0.0 & 0.0 & 0.5 & 1.0 & 0.0 & 0.0 & 0.0 \\
\hline 0.0 & 0.0 & 0.0 & 0.5 & 1.0 & 0.5 & 0.0 & 0.0 \\
\hline+0.05 & 0.0 & 0.0 & 0.0 & 1.0 & 0.5 & 0.0 & 0.0 \\
\hline+0.1 & 0.0 & 0.0 & 0.0 & 0.5 & 1.0 & 0.5 & 0.0 \\
\hline+0.2 & 0.0 & 0.0 & 0.0 & 0.5 & 0.5 & 1.0 & 0.0 \\
\hline+1.0 & 0.0 & 0.0 & 0.0 & 0.0 & 0.0 & 0.5 & 1.0 \\
\hline
\end{tabular}

By virtue of basic results in theory of fuzzy relational equations, the fuzzy relation of the control rules is given by:

$$
R\left(\Delta \omega_{i}, \Delta \dot{\omega_{i}}, u_{i}\right)=\max _{u \varepsilon U}\left(\min \left(\mu_{A}\left(\Delta \omega_{i}\right), \mu_{B}\left(\Delta \omega_{i}^{\bullet}\right), U\left(u_{i}\right)\right)\right)
$$


where :

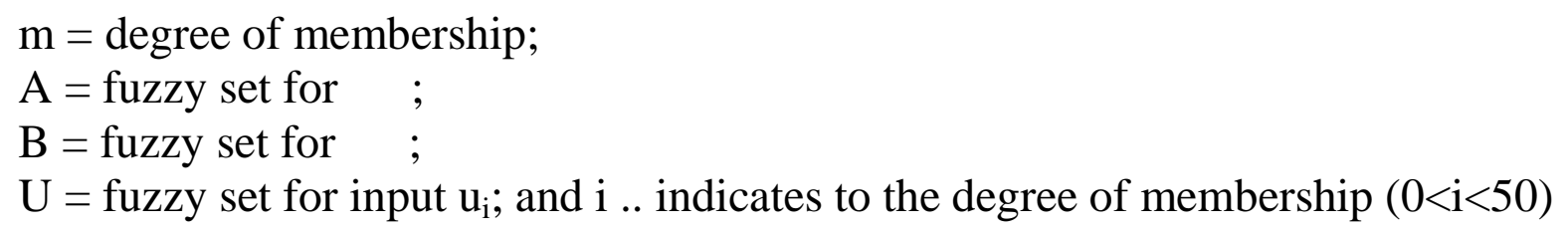

For appropriate control signals, we define crisp values for the control output corresponding to the different fuzzy subsets LN, MN, SN, VS, SP, MP, or LP. These crisp values are given in Table (3). After the membership function values are constructed appropriately for input and output signals (shown in Tables 2 and 3) and the fuzzy relation is defined in Equation (9), the fuzzy logic controller can be used for power systems stability enhancement. It has been reported that fuzzy-logic-based controllers performs better than conventional FLC [8].

Table (3): Crisp outputs w.r.t. fuzzy subsets

\begin{tabular}{|l||c|c|c|c|c|c|c||}
\hline Fuzzy Sets & LN & MN & SN & VS & SP & MP & LP \\
\hline \hline Crisp Value & -1.2 & -0.8 & -0.2 & 0.0 & 0.2 & 0.8 & 1.2 \\
\hline
\end{tabular}

\section{AFLC:}

There are many approach variants of the self-tuning problematic of fuzzy adaptive controllers [9-10]. A first method consists in the use of some scaling factors (online tunable) on the inputs and respectively, on the output of the fuzzy controller. Another method consists in the modification the membership function allure, through a suitable tuning of their parameter's values. The last mentioned method is the one used in the present paper. In Figure (2) is presented the Simulink block diagram of the considered control structure. The output's error represents the main variable, on which relays the online adjusting of controller's parameter by the tuning algorithm [11-12]. The implementation and simulation of control structure has been done with MatlabSimulink, considering the case of a single tunable parameter (the strategy can be easily generalized also for all other parameters). The on-line tuning algorithm of a parameter is implemented through a bipositional component, which briefly describes the following tasks (in this case, the 'c' parameter corresponding to the control's variable singletons):

- If the output's error remains in the specified values range, it maintains a constant value $\mathrm{c} 1$ for ' $c$ ' parameter (experimental off-line determined value).

- If the output's error exceeds the values range, the ' $c$ ' parameter is tuned to a new value $\mathrm{c} 2$, and this value is maintained until the output's error decreases under a value (closed to zero) [13]. 

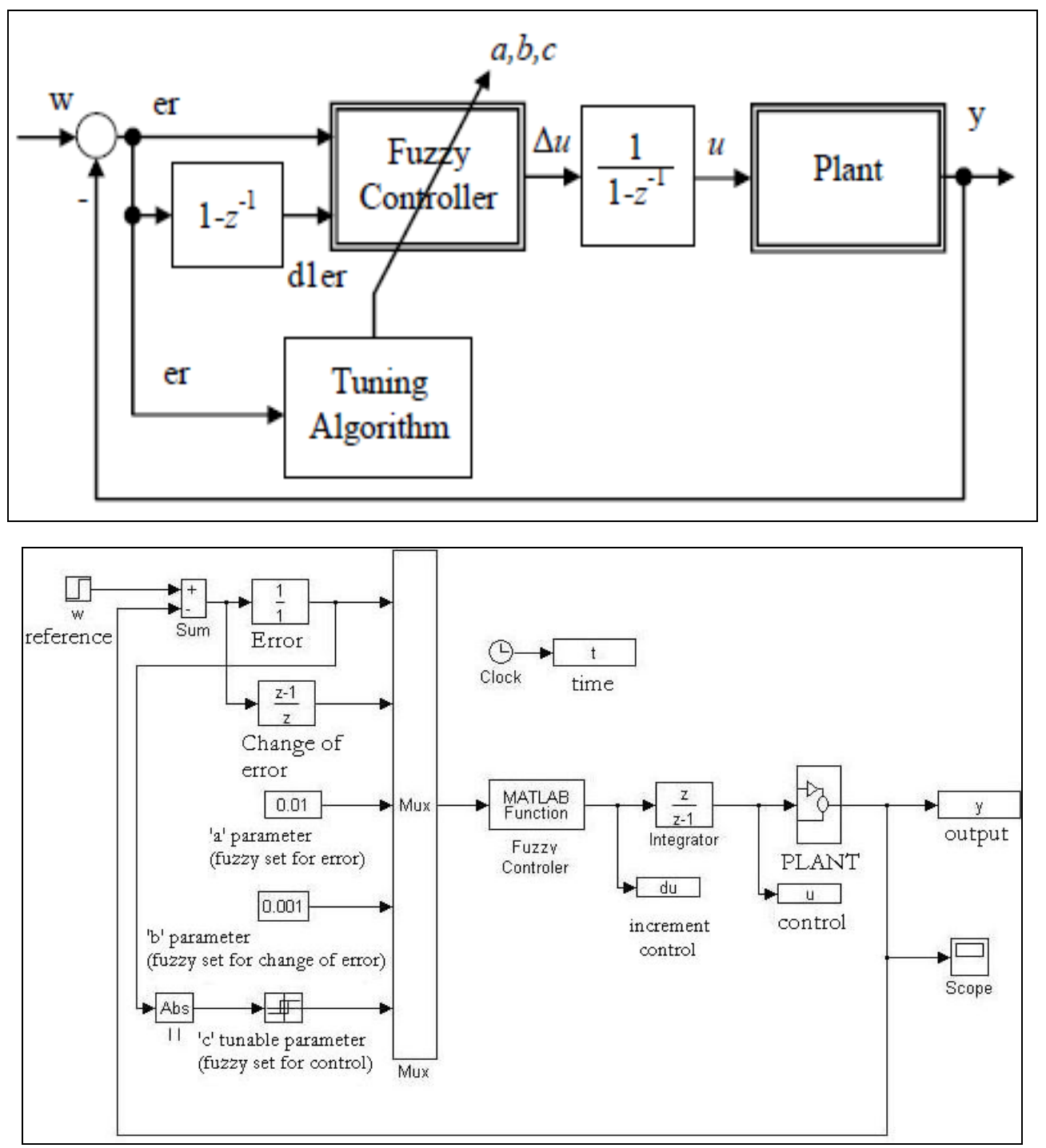

Figure (2): Adaptive PI-FLC Structure with Simulink model

\section{ANFLC:}

The neuro-fuzzy logic controller is a combination of a fuzzy logic controller and a neural network, which makes the controller self tuning and adaptive. Figure (3) depicts the neuro-fuzzy logic controller with controlled system. To find the optimal values of the NF parameters (premise and consequent parameters) for driving the plant to meet all control objectives, an optimal Fractional Order PID (FOPID) controller should be designed. The input/output data which will be obtained from FOPID controller design should be used to train the NF controller [14].

Once a fuzzy controller is transformed into an adaptive network, the resulting ANFLC can take advantage of all the neural network (NN) controller design techniques 
proposed in the literature [15]. Most of these methodologies are derived directly from counterparts for NN controllers. Essentially, the adaptive network is a superset of multilayer feed forward NNs with supervised learning capability. The block diagram of a feedback stabilizing system is shown in Figure (4) [16].

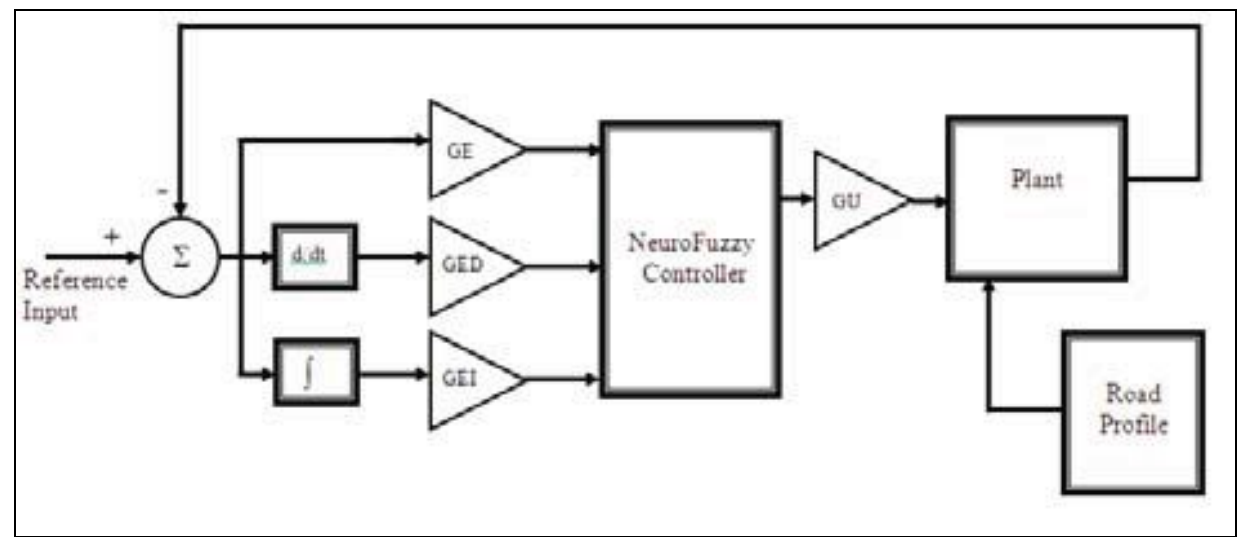

Figure (3): Neuro-fuzzy logic controller
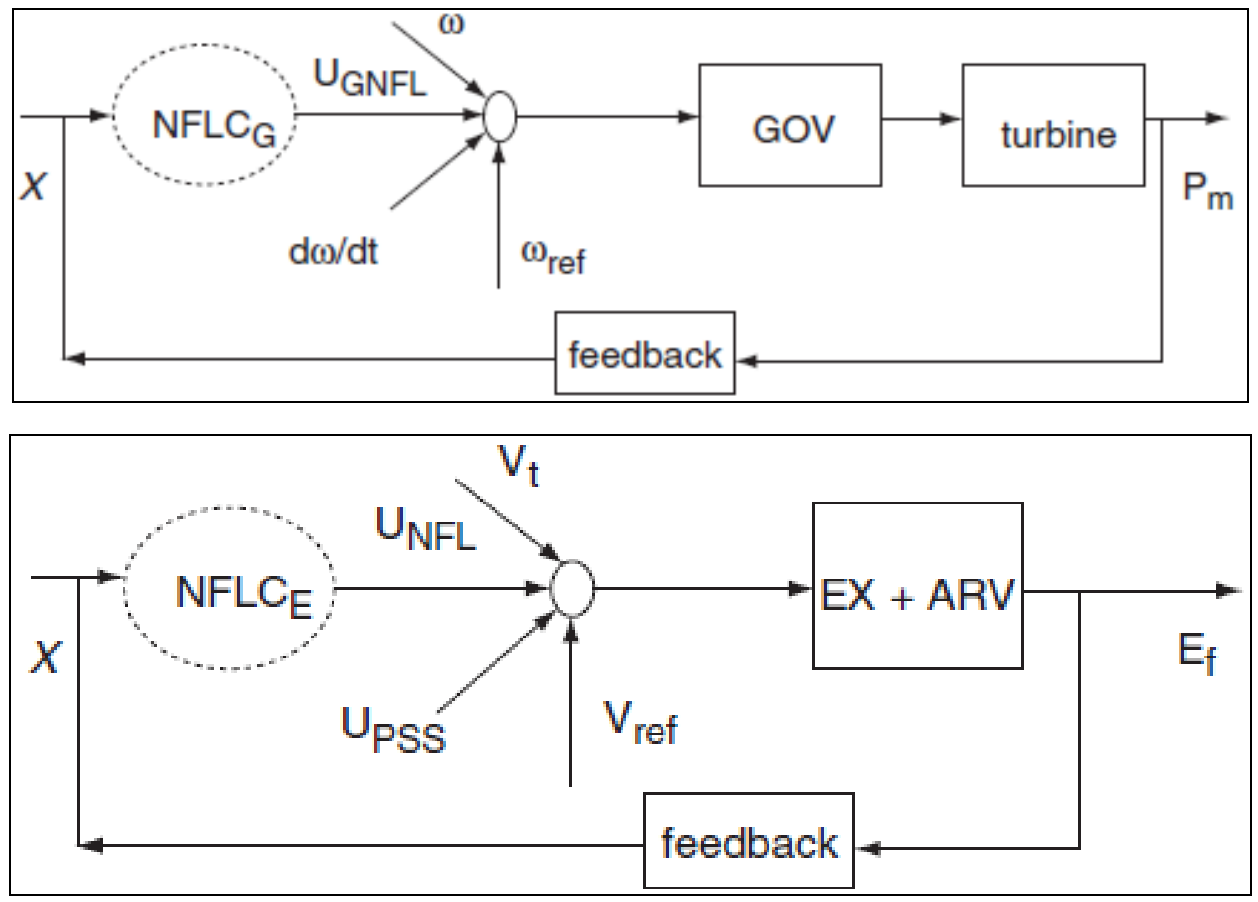

Figure (4): Overall control system

\section{TSFLC:}

In order, a Takagi-Sogeno proposed with two inputs; speed deviation ( $\omega$ ) and acceleration ( $\dot{\omega})$ of the rotor of synchronous generator were taken as the inputs with triangle membership function and one output with constant value. This output added to 
the voltage of AVR for accomplish the stability enhancement and damped out of the low frequency oscillations to approach a good and fast stability. The simulation results earned under different changes in inputs and parameters of power system. Generally triangle or trapezoidal membership functions are used [17]. Here a triangular membership function is used to define the degree of membership. In this case study we determined a symmetrical triangular membership function for two inputs as shown in Figure (5). The output range is between $[-1,1]$ and they have a constant and crisp values for the Takagi-Sugeno fuzzy controller. Figure (6) depicts the membership function of outputs. The output variable in Takagi-Sugeno fuzzy rules is given in terms of a functional relation of the inputs [18].

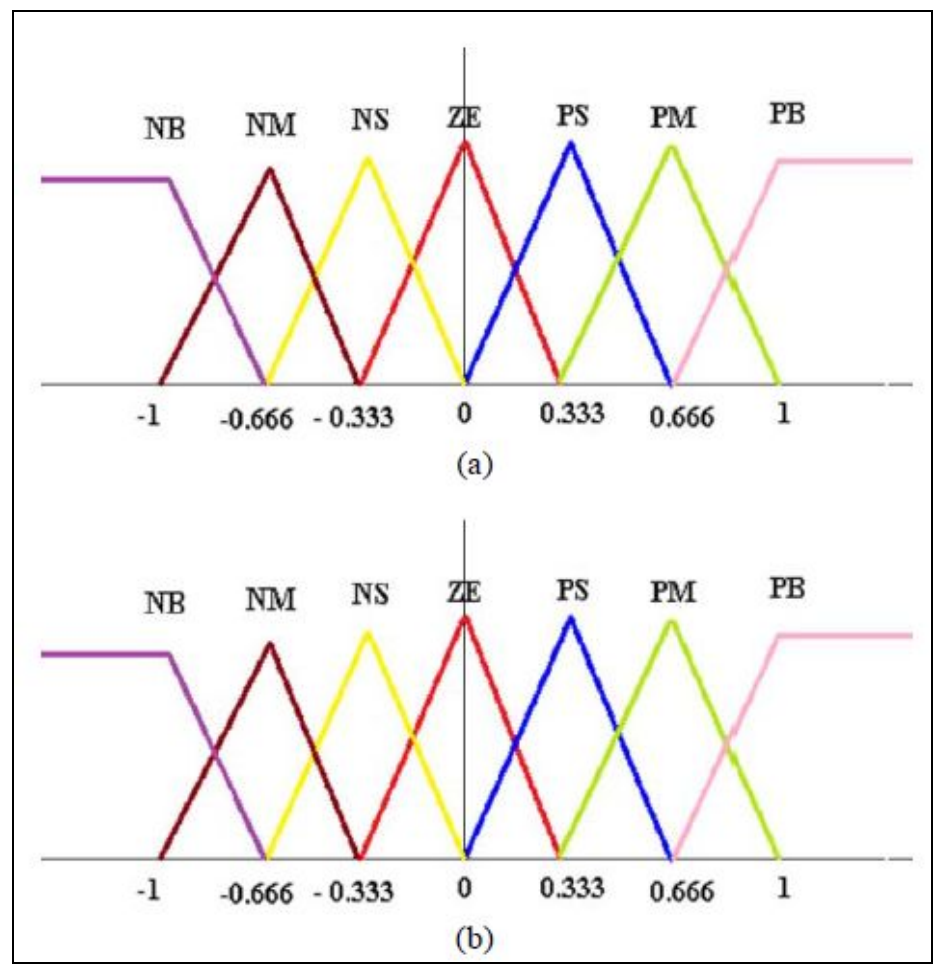

Figure (5): The membership function of inputs; (a) $\quad \omega,(b) \quad \dot{\omega}$

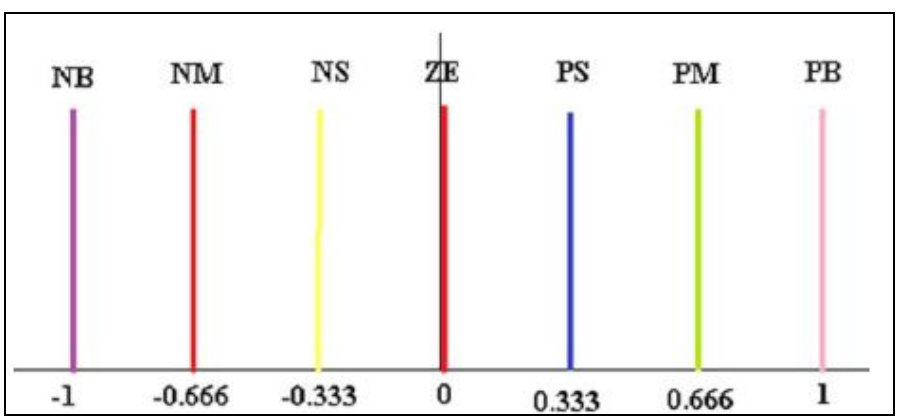

Figure (6): The membership function of outputs 


\section{Simulation Results:}

The synchronous machine connected to an infinite bus and shown in Figure (1) is modeled and simulated. The synchronous machine is connected to an infinite bus through double transmission lines. The complete data of this system is given in Appendix [B]. The overall system is tested under five different loading conditions as shown in Table (4). To validate the effectiveness of the four mentioned controllers, time response of rotor angle deviation for $10 \%$ increase in load power are drawn at the five different operating conditions. In each case the responses of the system with the four mentioned controllers are given in Figures $(7,8,9,10$, and 11). It can be concluded from these results that the system with TSFLC give best accuracy response and give good performance than the others three controllers.

Table (4): Loading conditions (in p.u.)

\begin{tabular}{|c|c|c|}
\hline Case & P & Q \\
\hline A & 0.2 & 0.6 \\
\hline B & 1.0 & 0.6 \\
\hline $\mathbf{C}$ & 1.2 & 0.6 \\
\hline $\mathbf{D}$ & 0.8 & 0.6 \\
\hline $\mathbf{E}$ & 1.2 & 0.8 \\
\hline
\end{tabular}

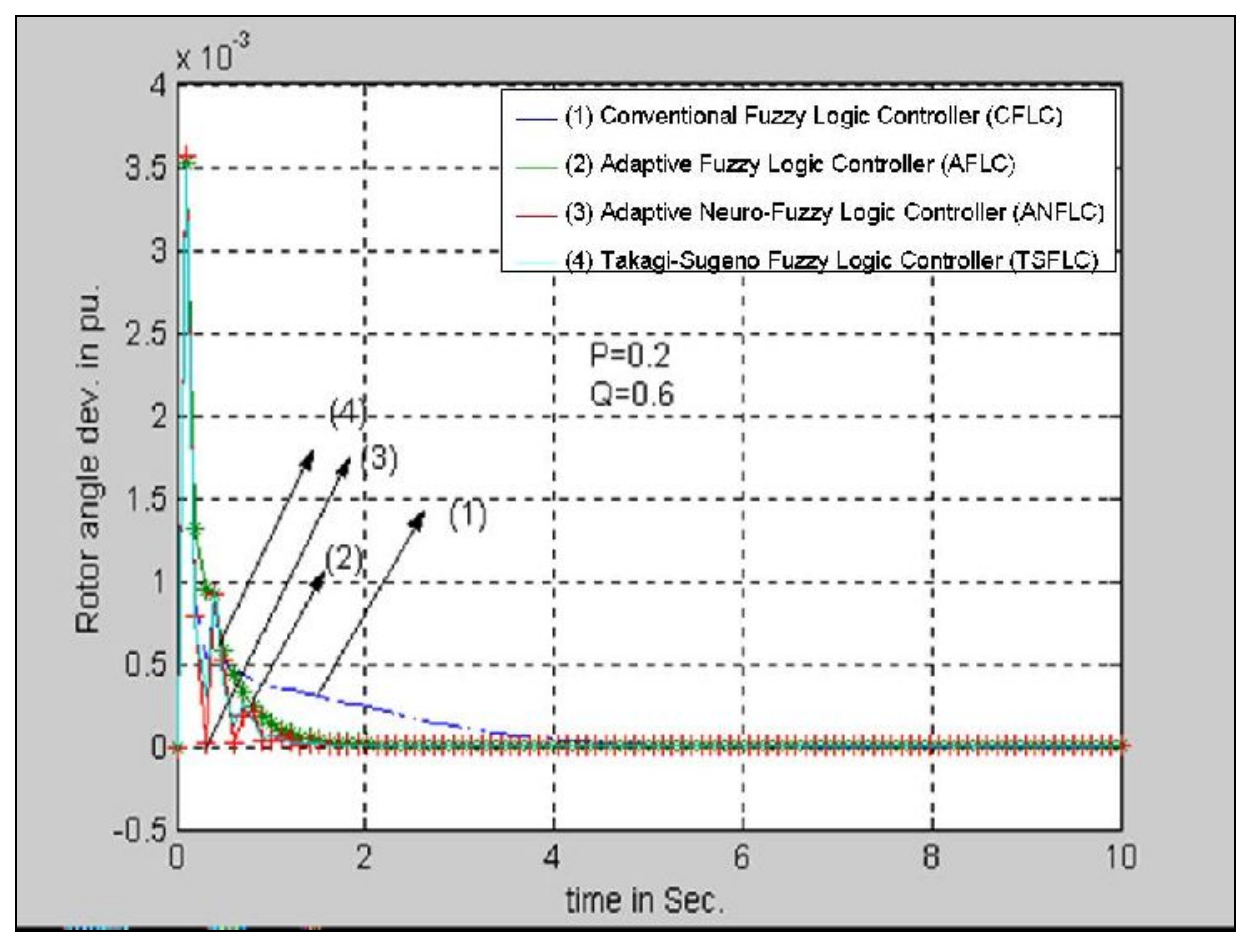

Figure (7): Rotor angle deviation response due to $10 \%$ load increase at loading condition (Case $A: P=0.2$ and $Q=0.6$ ) 


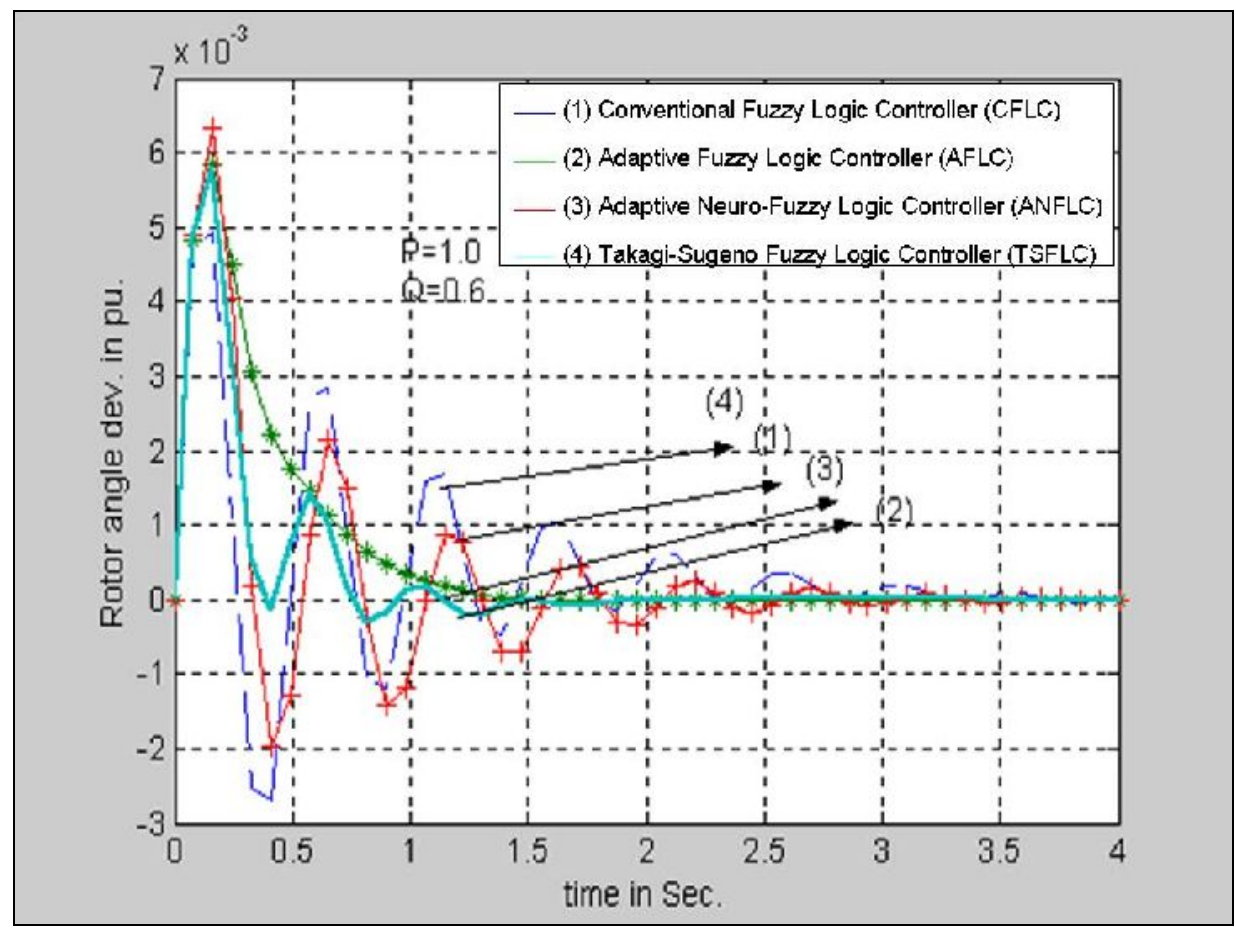

Figure (8): Rotor angle deviation response due to $10 \%$ load increase at loading condition (Case B: $P=1.0$ and $Q=0.6$ )

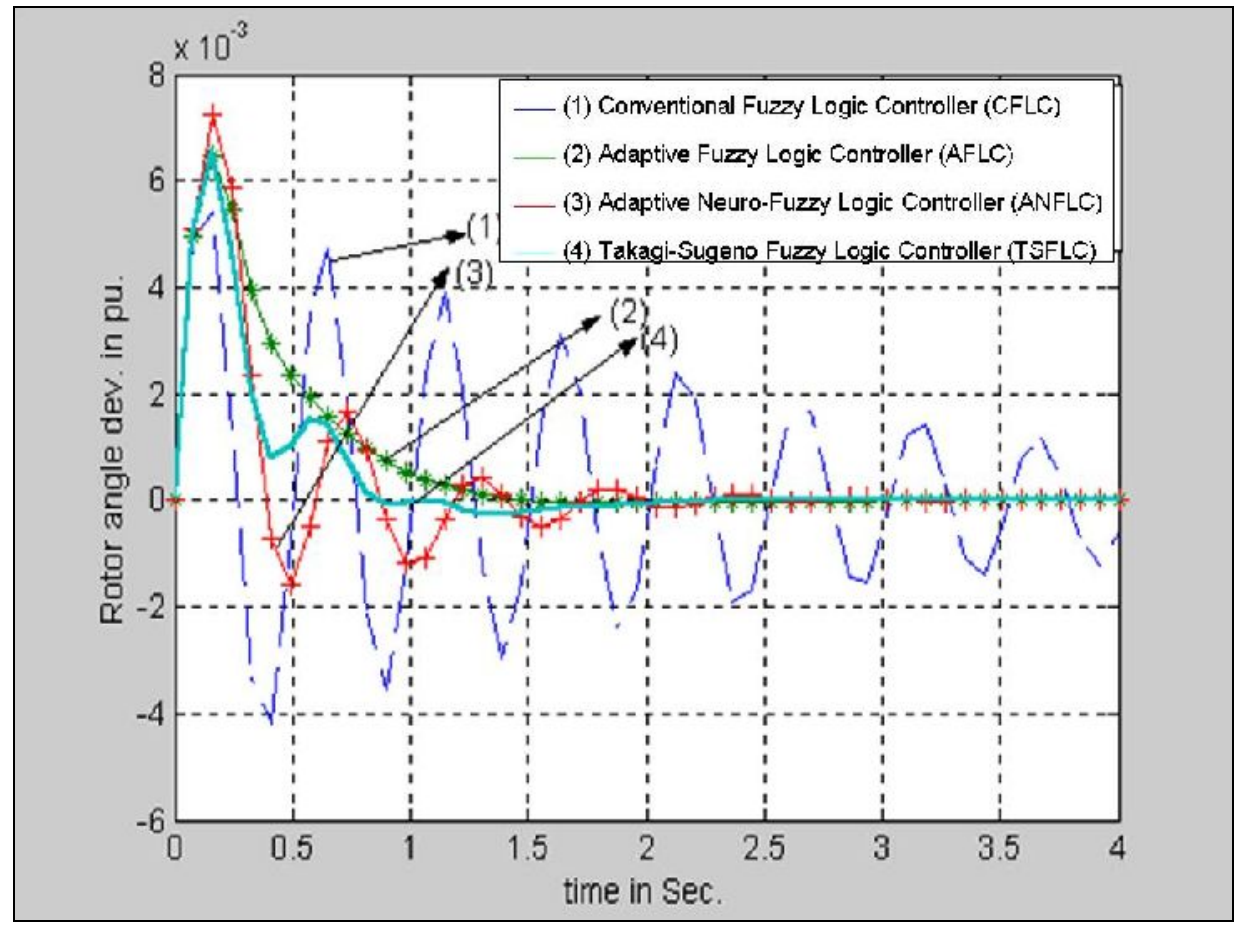

Figure (9): Rotor angle deviation response due to $10 \%$ load increase at loading condition (Case $C: P=1.2$ and $Q=0.6$ ) 


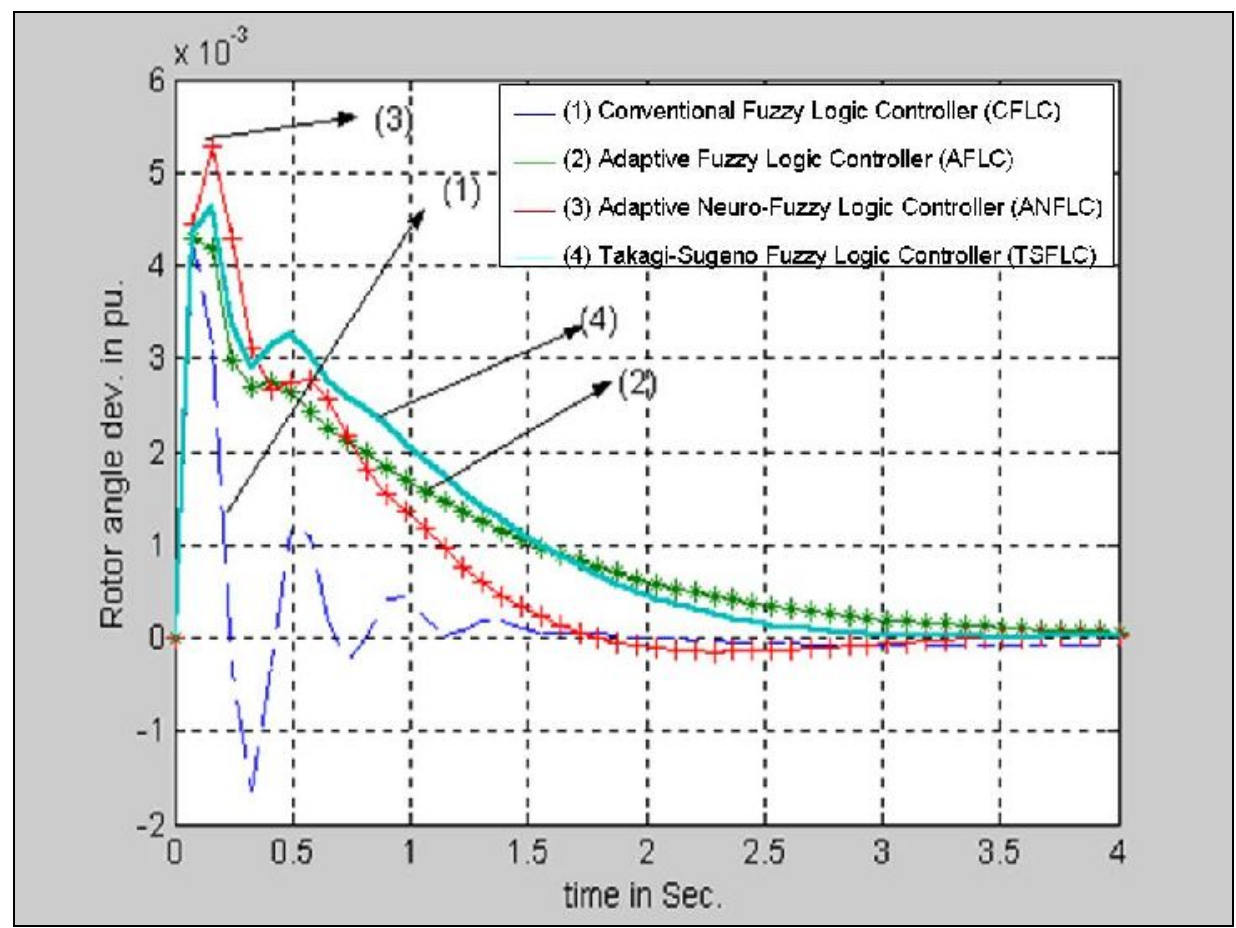

Figure (10): Rotor angle deviation response due to $10 \%$ load increase at loading condition (Case $D: P=0.8$ and $Q=0.6$ )

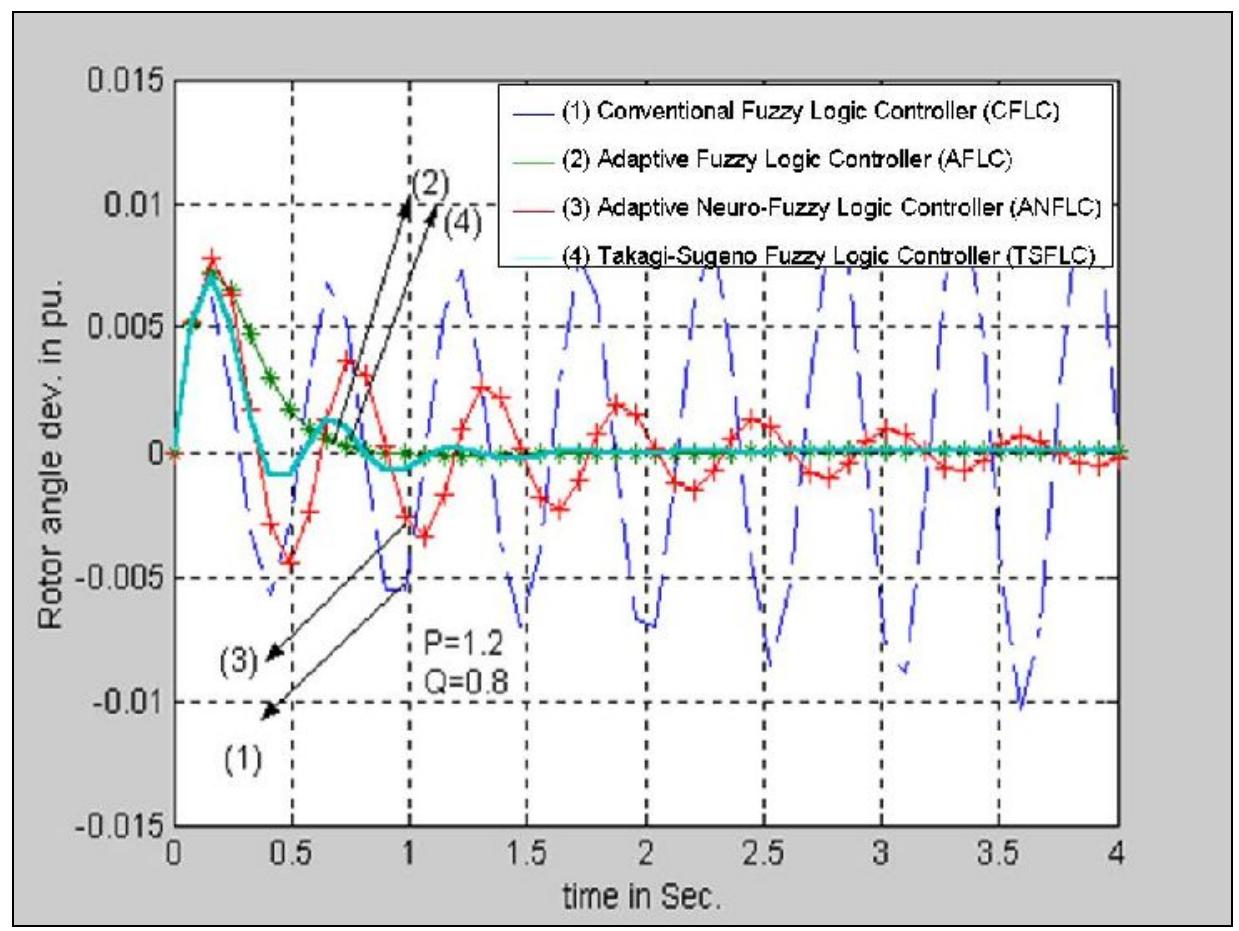

Figure (11): Rotor angle deviation response due to 10\% load increase at loading condition (Case $E: P=1.2$ and $Q=0.8$ ) 
The results demonstrated in the curves of Figures (7) to (11), illustrate that the general quality of operation and application of a coordinated control of FLPSS-AVR applied for a power system, is most effective. The Figures show that the quality of this controller will offer a new addition to the conventional controllers. Results show that there is still an area for investigating the application of different control strategies using different controllers, such as TSFLC, at different locations in the power network for attaining better stability characteristics. Also, the results show that a fast coordinated control such as the one with FLPSSs is more suitable for damping system oscillations for having the system intact than the case with the machine controlled with effective AVR and PSS at all times. A conventional AVR control at some locations with effective PSS at other locations may be most suitable for keeping some severe transient conditions. This effectiveness differs between the four mentioned controllers: CFLC, AFLC, ANFLC, and TSFLC.

From the figures it's clear that there is an improvement in response during transient period. Also, the oscillations are dimensioned after about 1.25 seconds and hence the dynamic and steady state stability coming in a faster way. So, the control technique proved its quality to damp the oscillations. It is clear that the effectiveness of the proposed control strategy in damping the system frequency (speed) oscillations. Also, it's noticed that, the proposed control strategy has the merit of existing strategies by the improvement in both transient and steady state stability. It can be concluded from these results that the power system with TSFLC give best accuracy response and give good performance than the others three controllers. The TSFLC showed high response when applied to power system. The TSFLC proved satisfactory dynamic performance. When the TSFLC is attached to the power system, its response behave as the PD controller.

\section{Conclusions:}

This paper presents an implementation of four different Fuzzy Logic based intelligent controllers through the excitation system of the synchronous machine connected to infinite bus: Conventional Fuzzy Logic Controller (CFLC), Adaptive Fuzzy Logic Controller (AFLC), Adaptive Neuro-Fuzzy Logic Controller (ANFLC) and TakagiSugeno Fuzzy Logic Controller (TSFLC). A comparison between the four proposed intelligent controllers are presented in order to improve the dynamic response of the system under study and to give an optimal performance at any loading condition. Also, these controllers are designed in order to retain only the states, which are measurable or observable. The obtained results show the effectiveness and good accuracy of the Takagi-Sugeno Fuzzy Logic Controller (TSFLC) in enhancing the damping characteristic of the studied system in comparison with the other three controllers types. 


\section{References:}

[1] A. Dysko, W. E. Leithead and J. O'Reilly, Enhanced Power System Stability by Coordinated PSS Design, IEEE Transactions on Power Systems, Vol. 25, No. 1, P. 413-422, 2010.

[2] H. Shayeghi, H. A. Shayanfar and A. Jalili, Load Frequency Control Strategies: A State-of-the-art Survey for the Researcher, Energy Conversion and Management, Vol. 50, No. 2, P. 344-353, 2009.

[3] M. Begovic, D. Novosel and M. Milisavljevic, Trends in Power System Protection and Control, SIAM J. Decision Support Systems, Vol. 30, No. 3, P. 269-278, 2001.

[4] O. P. Malik, Amalgamation of Adaptive Control and AI Techniques: Applications to Generator Excitation Control, Annual Reviews in Control, Vol. 28, No. 1, P. 97-106, 2004.

[5] Fang Shi, and Jie Wang, Robust Coordinated Control of Excitation and SVCs in Multi-Machine Power System, International Review of Electrical Engineering, Vol. 8, No. 1, P. 340-345, Jan/Feb 2013.

[6] G. H. Hwang et al., Design of Fuzzy Power System Stabilizer using Adaptive Evolutionary Algorithm, Engineering Applications of Artificial Intelligence, Vol. 21, No. 1, P. 86-96, 2008.

[7] W. Sabry, A Comparison between Conventional and Optimal Power System Stabilizers for a Single Machine to an Infinite Bus Power System, International Journal on Power Engineering and Energy (IJPEE), Vol. 4, No. 1, P. 361-363, 2013.

[8] Momoh, J. A., X. W. Ma, and K. Tomsovic, Overview and Literature Survey of Fuzzy Set Theory in Power Systems, IEEE Trans. on Power Systems, Vol. 10, No. 3, P. 1676-1690, Aug. 1995.

[9] T. Takagi, and M. Sugeno, Fuzzy Identification of Systems and its applications to Modeling and control, IEEE Trans. Systems, Man and Cybernetics, Vol. 15, P. 116-132, 1985. 
[10] K. A. El-Metwally, and O. P. Malik, Fuzzy Logic Power System Stabilizer, IEE Proceedings - Generation, Transmission and Distribution, Vol. 142, No. 3, P. 277-281, 1995.

[11] S. A. Gawish, F. A. Khalifa, M. A. L. Badr, and W. Sabry, Large Power Systems Stability Enhancement using a Delayed Operation Fuzzy Logic Power System Stabilizer, Electric Machines and Power Systems, Vol. 27, No. 2, P. 157-168, 1999.

[12] M. A. L. Badr, F. A. Khalifa, S. A. Gawish, and W. Sabry, Large-Scale Power System Transient and Dynamic Stability using Delayed-Operation FLPSS-AVR Controller Coordination, Canadian Journal of Electrical and Computer Engineering (CJECE), Vol. 26, No. 2, P. 61-64, 2001.

[13] P. Hoang, and K. Tomsovic, Design and Analysis of an Adaptive Fuzzy Power System Stabilizer, IEEE Trans. on Energy Conversion, Vol. 11, No. 2, P. 455-461, June 1996.

[14] A. Aldair, and W. J. Wang, Adaptive Neuro Fuzzy Inference Controller for Full Vehicle Nonlinear Active Suspension Systems, Iraq J. Electrical and Electronic Engineering, Vol. 6, No. 2, P. 97-106, 2010.

[15] Z. Barton, Robust Control in a Multimachine Power System using Adaptive Neuro-Fuzzy Stabilisers, IEE Proceedings - Generation, Transmission and Distribution, Vol. 151, No. 2, P. 261-267, March 2004.

[16] D. A. Linkens, and Ali A. Afzalian, A Neuro-Fuzzy Power System Stabiliser, International Conference on Intelligent and Cognitive Systems, P. 106-111, September 1996.

[17] Reghunadhan Rajesh, and M. Ramachandra Kaimal, Variable Gain TakagiSugeno Fuzzy Logic Controllers, INFORMATICA, Vol. 17, No. 3, P. 427-444, 2006.

[18] Budiman Azzali Basir, Mohammad Noh Ahmad, and Abd. Rashid Hussain, Takagi Sugeno Fuzzy Sliding Mode Controller Design for a Class of Nonlinear System, Australian Journal of Basic and Applied Sciences, Vol. 7, No. 7, P. 395400, 2013. 


\section{Nomenclatures:}

$\mathrm{K}_{\mathrm{a}} \quad \ldots \quad$ Amplifier gain

$\mathrm{K}_{\mathrm{e}} \quad \ldots$ Exciter gain

$\mathrm{K}_{\mathrm{r}} \quad \ldots \quad$ AVR gain

$\mathrm{K}_{\mathrm{s}} \quad \ldots \quad$ Exciter stabilizer gain

M ... Inertia constant

$\mathrm{R}_{\mathrm{g}} \quad$... Steady state speed governor regulation

$\mathrm{r}_{1} \quad \ldots$ Transmission lines resistance

$\mathrm{T}_{\mathrm{a}} \quad \ldots$ Amplifier time constant

$\mathrm{T}_{\mathrm{e}} \quad \ldots$ Exciter time constant

$\mathrm{T}_{\mathrm{g}} \quad \ldots$ Governor time constant

$\mathrm{T}_{\mathrm{r}} \quad \ldots \quad$ AVR time constant

$\mathrm{T}_{\mathrm{s}} \quad \ldots \quad$ Exciter stabilizer time constant

$\mathrm{T}_{\mathrm{t}} \quad \ldots$ Steam turbine time constant

$\mathrm{x}_{\mathrm{d}} \quad \ldots \quad \mathrm{d}$-axis reactance

$\mathrm{x}_{\mathrm{fd}} \quad \ldots \quad$ Field winding reactance

$\mathrm{x}_{\mathrm{kd}} \quad \ldots \quad \mathrm{d}$-axis damper winding reactance

$\mathrm{x}_{\mathrm{kq}} \quad \ldots \quad \mathrm{q}$-axis damper winding reactance

$\mathrm{x}_{1} \quad \ldots \quad$ Transmission lines reactance

$\mathrm{x}_{\mathrm{md}} \quad \ldots \quad \mathrm{d}$-axis mutual reactance

$\mathrm{x}_{\mathrm{mq}} \quad \ldots \quad \mathrm{q}$-axis mutual reactance

$\mathrm{x}_{\mathrm{q}} \quad \ldots \quad \mathrm{q}$-axis reactance

\section{Appendix [A]: Elements of A-matrix}

$$
\begin{array}{ccc}
\psi_{d 0}=-x_{d} I_{d 0}+x_{m d} I_{f 0} & \psi_{q 0}=x_{q} I_{q 0} & M 10,1=\frac{K_{r} V_{q 0} r_{l}-K_{r} V_{d 0} x_{l}}{T_{r} V_{t 0}} \\
M 10,2=\frac{K_{r} V_{q 0} x_{l}-K_{r} V_{d 0} r_{l}}{T_{r} V_{t 0}} & M 10,6=\frac{K_{r} V_{q 0} V_{b} \sin \delta_{0}+K_{r} V_{d 0} V_{b} \cos \delta_{0}}{T_{r} V_{t 0}} & M 10,7=\frac{K_{r} V_{q 0} I_{d 0} x_{l}-K_{r} V_{d 0} I_{q 0} x_{l}}{T_{r} V_{t 0}} \\
\psi_{d 0}=-x_{d} I_{d 0}+x_{m d} I_{f 0} & \psi_{q 0}=x_{q} I_{q 0} & M 10,1=\frac{K_{r} V_{q 0} r_{l}-K_{r} V_{d 0} x_{l}}{T_{r} V_{t 0}} \\
M 10,2=\frac{K_{r} V_{q 0} x_{l}-K_{r} V_{d 0} r_{l}}{T_{r} V_{t 0}} & M 10,6=\frac{K_{r} V_{q 0} V_{b} \sin \delta_{0}+K_{r} V_{d 0} V_{b} \cos \delta_{0}}{T_{r} V_{t 0}} & M 10,7=\frac{K_{r} V_{q 0} I_{d 0} x_{l}-K_{r} V_{d 0} I_{q 0} x_{l}}{T_{r} V_{t 0}}
\end{array}
$$

\section{Appendix [B]: System Parameters}

Parameters of the synchronous machine that connected to infinite bus power system (in p.u.):

\begin{tabular}{|r|l|r|l|}
\hline $\mathbf{x}_{\mathbf{q}}$ & 1.563 & $\omega_{\mathbf{b}}$ & 377 \\
\hline $\mathbf{x}_{\mathbf{d}}$ & 1.653 & $\mathbf{M}$ & 0.014 \\
\hline $\mathbf{x}_{\mathbf{m q}}$ & 1.47 & $\mathbf{D}$ & 0.0 \\
\hline $\mathbf{x}_{\mathbf{m d}}$ & 1.56 & $\mathbf{R}_{\mathbf{g}}$ & 18.85 \\
\hline $\mathbf{x}_{\mathbf{k q}}$ & 1.502 & $\mathbf{T}_{\mathbf{g}}$ & 0.25 \\
\hline
\end{tabular}




\begin{tabular}{|r|l|l|l|}
\hline $\mathbf{x}_{\mathbf{k d}}$ & 1.608 & $\mathbf{T}_{\mathbf{t}}$ & 1 \\
\hline $\mathbf{x}_{\mathbf{f d}}$ & 1.646 & $\mathbf{K}_{\mathbf{e}}$ & 13.89 \\
\hline $\mathbf{x}_{\mathbf{l}}$ & 0.2 & $\mathbf{K}_{\mathbf{a}}$ & 50 \\
\hline $\mathbf{r}_{\mathbf{a}}$ & 0.0032 & $\mathbf{K}_{\mathbf{r}}$ & 1 \\
\hline $\mathbf{r}_{\mathbf{f d}}$ & 0.001 & $\mathbf{K}_{\mathbf{s}}$ & 0.057 \\
\hline $\mathbf{r}_{\mathbf{k d}}$ & 00.011 & $\mathbf{T}_{\mathbf{e}}$ & 02. \\
\hline $\mathbf{r}_{\mathbf{k q}}$ & 00.014 & $\mathbf{T}_{\mathbf{a}}$ & 0.02 \\
\hline $\mathbf{r}_{\mathbf{l}}$ & 0.02 & $\mathbf{T}_{\mathbf{r}}$ & 0.001 \\
\hline $\mathbf{V}_{\mathbf{b}}$ & 1 & $\mathbf{T}_{\mathbf{s}}$ & 0.45 \\
\hline
\end{tabular}

